\title{
Durability of carbon fibre reinforced polymer laminates used to reinforced concrete structures
}

\author{
Susana Cabral-Fonseca1,*, João Pedro Nunes ${ }^{2}$, \\ Maria Paula Rodrigues ${ }^{1}$ and Maria Isabel Eusébio ${ }^{1}$ \\ ${ }^{1}$ Laboratório Nacional de Engenharia Civil, Av. do Brasil, \\ 101, 1700-066 Lisbon, Portugal, e-mail: sbravo@lnec.pt \\ ${ }^{2}$ Polymer Engineering Department, Campus de Azurém, \\ University of Minho, 4800-058 Guimarães, Portugal
}

*Corresponding author laminates, but also for a better understanding of the degradation mechanisms involved, which is a base for the design of service life-prediction models.

Keywords: carbon fibre reinforced polymer; concrete structures; durability; rehabilitation.

\section{Introduction}

The repair and strengthening of deteriorated, damaged and old infrastructures has become an important civil engineering challenge worldwide [1]. One of the most popular techniques used to rehabilitate concrete structures is the external bonding of carbon fiber reinforced polymer (CFRP) laminates to them. Epoxy resins are usually selected as structural bonding adhesives. The use of CFRP laminates in these applications is based on their excellent attributes, such as lightweight, high stiffness and strength-to-weight ratios, easy field installation, lower maintenance costs and potentially high overall durability [2]. The much larger use of such repairing solutions enhanced the elaboration of new application guidelines and codes [3, 4], as well as standards and specifications nowadays $[5,6]$.

However, since composite materials still are relatively unknown to engineers great concerns subsist about their overall durability, especially related to the ability of these materials to sustain performance under harsh and changing environmental conditions [7, 8]. In fact, civil engineering structures are often highly contaminated by different environmental agents like rain, saline water, ground water and high alkalinity solutions generated by the concrete chemical compositions itself [9]. The durability of concrete structures reinforced with externally bonded FRP composites shall be analysed at two levels: (i) the durability of FRP material itself and (ii) the durability of the bond between the FRP material and the If and the durability of the bond between the FRP material and the concrete substrate. Intrinsically the latter includes the durability of the resin/adhesive layer at the interface between the FRP composite and the concrete substrate.

The work described in this paper is part of a research study that is being made to predict the long-term behaviour of several commercial CFRP laminate/adhesive systems used in concrete structures rehabilitation. In the whole project it is recognised that the durability of this rehabilitation scheme depends, not only on the durability of the materials involved but also the performance of the bonding between concrete and the reinforcement system. The present document provides details about the part of the investigation concerning the durability of CFRP laminates. 


\section{Materials and methods}

\subsection{Materials}

Three commercial CFRP laminates used to reinforce externally concrete structures by adhesive bonding were selected to be studied in the present work. Along this document, the letters $\mathrm{A}, \mathrm{B}$ and $\mathrm{C}$ will designate each one of the laminates chosen. Specimens cut in the longitudinal direction of the original laminates were submitted to the different tests made, after ageing.

\subsection{Methods}

2.2.1. Accelerated ageing schedule In order to investigate the environmental effects on CFRP laminates, it was performed an ageing schedule described in Table 1.

2.2.2. Material characterisations before and after aging After exposure to different ageing conditions presented in Table 1, test CFRP laminates were subjected to the following tests:

1. Mass changes: Control specimens, were removed periodically from exposure to evaluate the mass changes.

2. Flexural testing (Instron 4483, Norwood, MA, USA): Three point bending flexural tests were conducted according to ISO 14125 [12] in CFRP laminates specimens using a spanto-depth ratio of 40 . The loading rate was $2 \mathrm{~mm} / \mathrm{min}$. At least five replicates were tested for each material and aging conditions.

3. Dynamic Mechanical Analysis (DMA) (TA Instrument DMA Q800, New Castle, DE, USA): DMA has been used to analyse the viscoelastic response of laminates and to assess the glass transition temperature $\left(T_{\mathrm{g}}\right)$, in accordance with ISO 6721 [13]. Single cantilever type clamp specimens were tested at the constant frequency of $1 \mathrm{~Hz}$ and strain amplitude of $10 \mu \mathrm{m}$. The analysis was carried out from room temperature to $200^{\circ} \mathrm{C}$, at a rate of $2^{\circ} \mathrm{C} / \mathrm{min}$.
Two replicates were tested for each material and aging condition.

4. Fourier transform infrared spectroscopy (FTIR) (NicoletThermoFisher Scientific, Magna 550 series II, Watertown, CT, USA): Infrared spectra of laminates, before and after ageing exposure, were studied in the $450 \mathrm{~cm}^{-1}$ and $4000 \mathrm{~cm}^{-1}$ region by using an Infrared Spectrometer. For these measurements, powder samples scraped from the surfaces of test specimens, were mixed with dry spectroscopic grade potassium bromide and pressed into pellets. Thirty-two scans were collected and averaged at a spectral resolution of $4 \mathrm{~cm}^{-1}$.

\section{Results and discussion}

\subsection{Mass change}

Figure 1 illustrated the mass variation measured during different immersion ageing (in water - IW; in saline solution IS and in alkaline solution - IL) and temperature conditions $\left(23^{\circ} \mathrm{C}, 40^{\circ} \mathrm{C}\right.$ and $60^{\circ} \mathrm{C}$ ) for the three laminates (A, B and C).

As may be seen, all laminates seem to reach a quasiequilibrium state after immersion in water and saline solution at room temperature, $40^{\circ} \mathrm{C}$ and $60^{\circ} \mathrm{C}$. At those temperatures the overall mass variation observed is always smaller than $1 \%$ for the three laminates. The rate of approach to equilibrium is more rapid at the highest immersion temperatures, as expected in a diffusion controlled process. Those results are consistent with others described for different types of polymeric composites [14].

For laminate $\mathrm{C}$, the alkaline solutions caused fairly higher variation of mass, than the other immersion liquids, at the same temperature.

The immersion in alkaline solutions shows a complete different scenario for laminates A and B. Laminate A shows a drastic initial mass increasing at higher immersion

Table 1 Aging schedule.

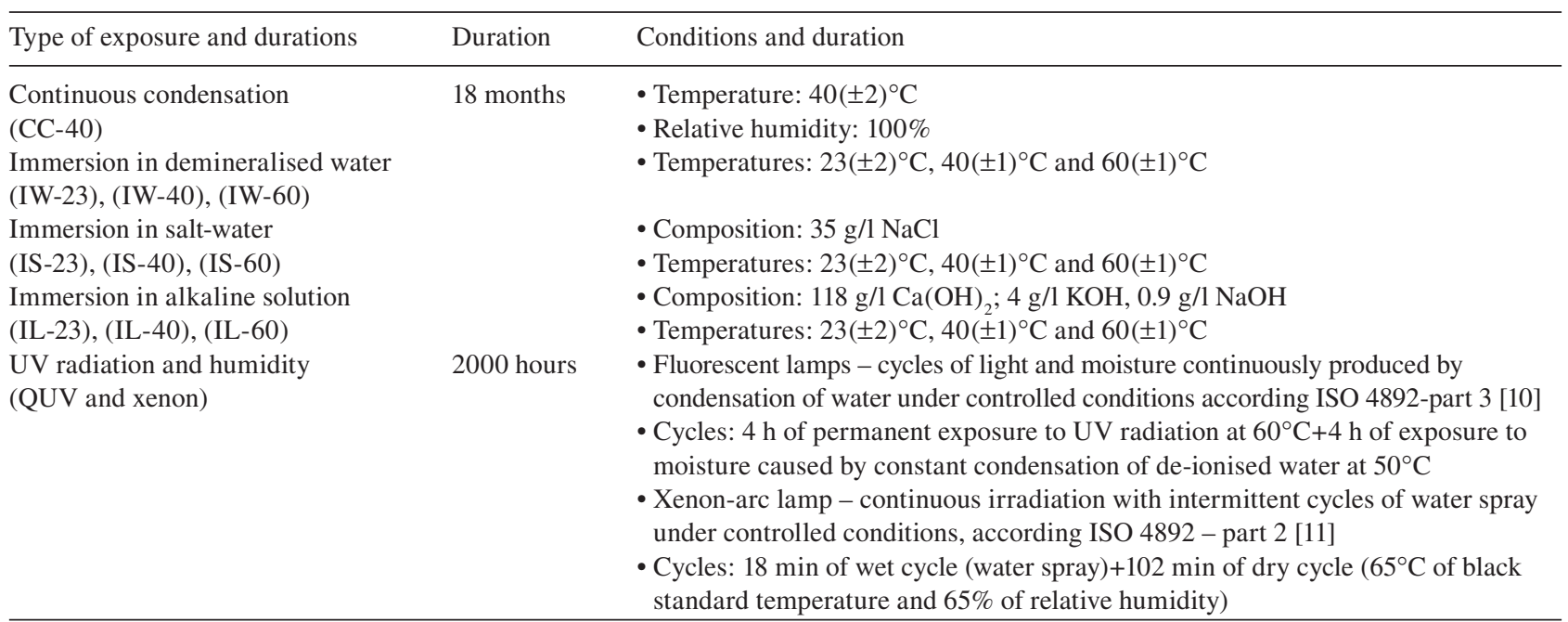



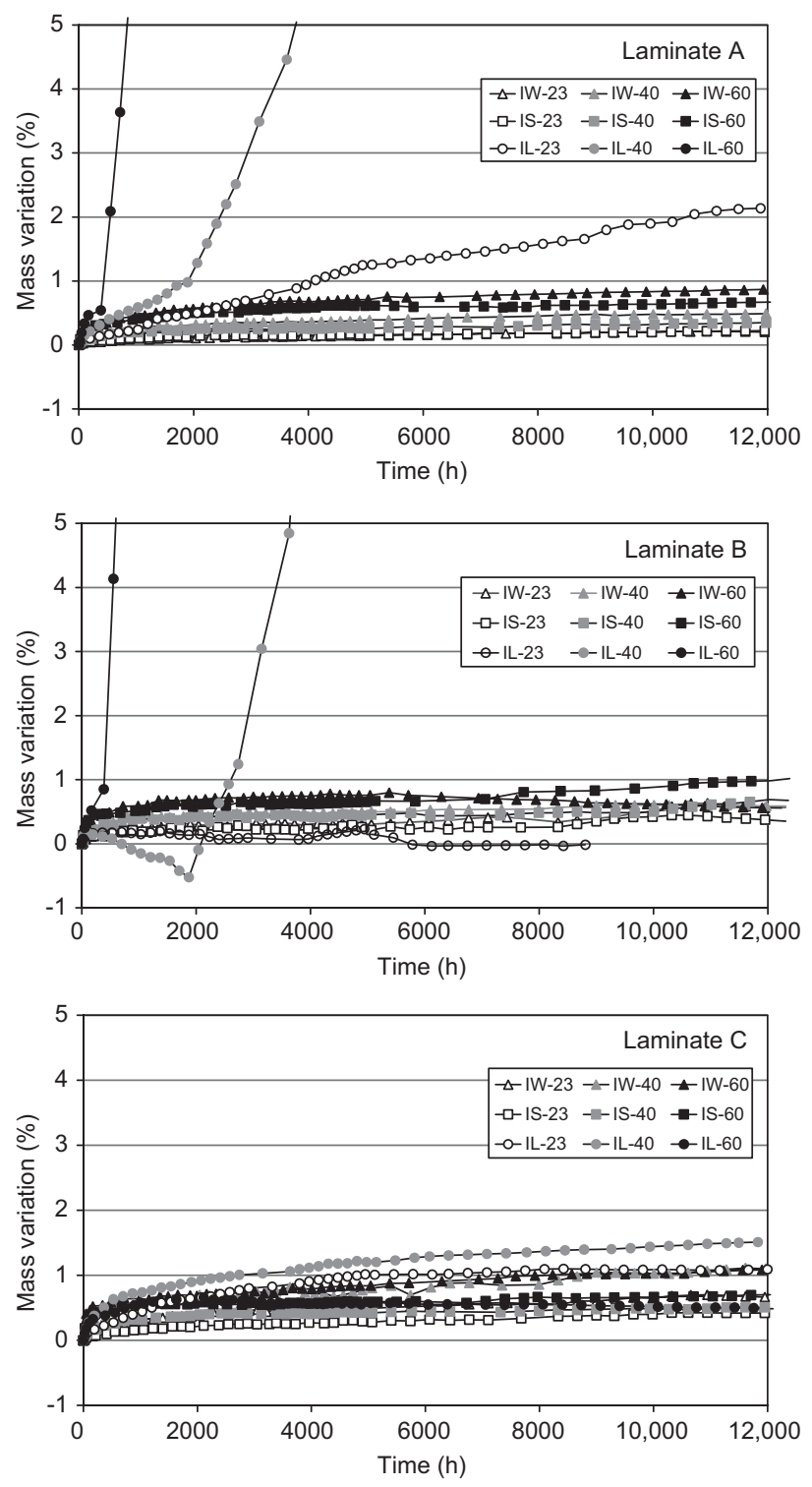

Figure 1 Mass variation of laminates during different immersion conditions.

temperatures and less expressive mass variations at room temperature. Laminate B shows insignificant mass variation at room temperature. This laminate immersed in the alkaline solution at $40^{\circ} \mathrm{C}$ shows an initially mass loss, followed by an unexpected rapid increasing. At $60^{\circ} \mathrm{C}$ the mass variations are very sharp. Those test specimens showed an important swelling during the increment of their mass.

In general, the performance of the laminates is much well distinguished at higher temperature in the alkaline solution and laminate $\mathrm{C}$ has shown to be the most performing one.

\subsection{Flexural properties}

All laminates exhibited a quite linear behaviour prior to failure and quite similar load-displacement experimental curve. The flexural properties (mean value \pm standard deviation) determined in the laminates after different ageing conditions are plotted in Figure 2. The flexural strength (in $\mathrm{MPa}$ ) and flexural modulus (in $\mathrm{GPa}$ ) are represented in those plots by bars and single squares, respectively. Laminates A and B were attacked by the alkaline solution, with the extraction of the polymeric matrix. For this reason, in some conditions it was impossible to perform the flexural tests.

An overall decrease in flexural properties was observed for every immersion liquid's conditions, for all laminates. Furthermore, higher temperature caused further degradation. In fact, water absorption seems to have had a noticeable influence on the reduction of flexural strength and this effect was increased by temperature.
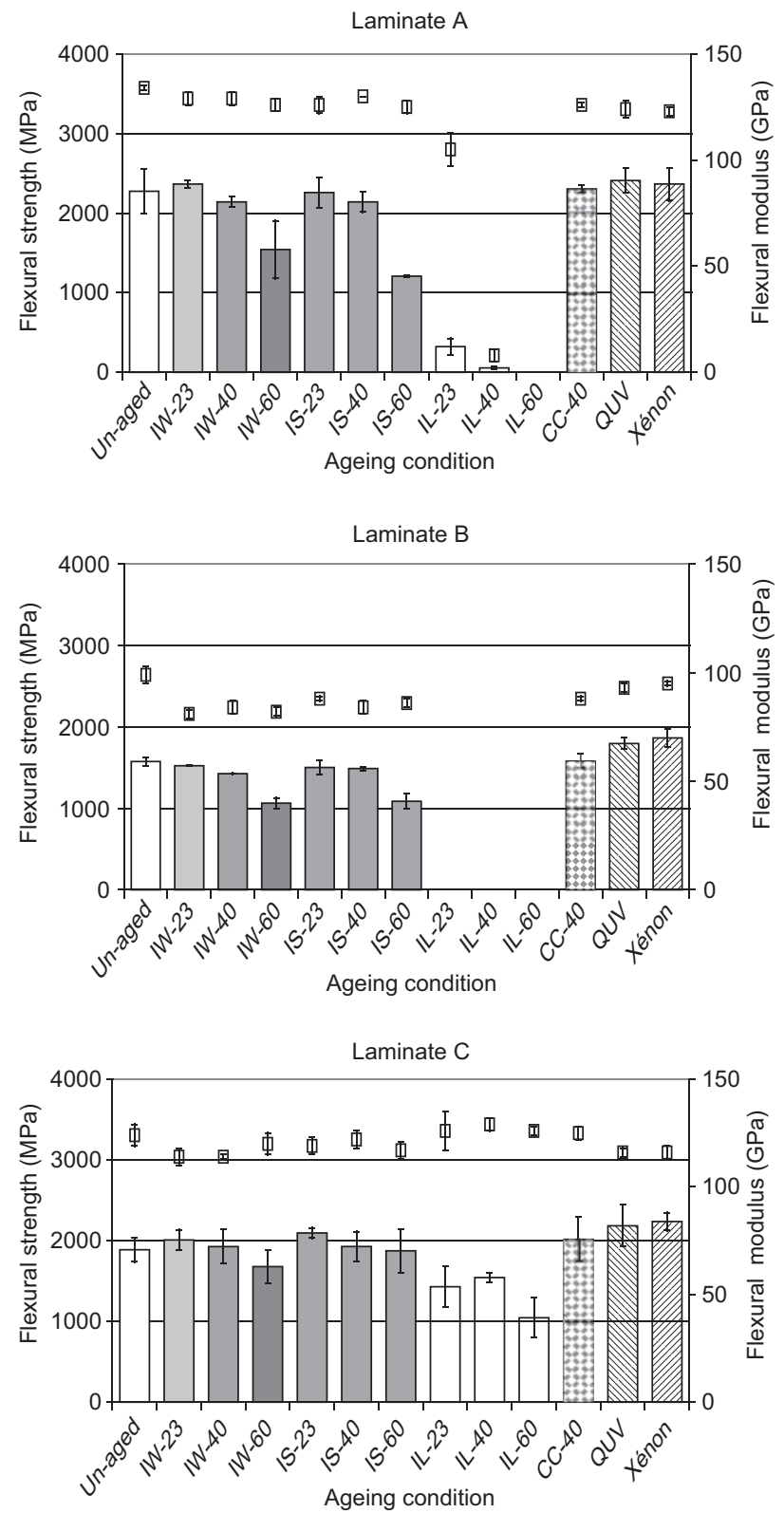

Figure 2 Flexural properties for laminates A, B and C before and after different ageing conditions. 
Laminates A and B presented a clear decreasing of the flexural strength after immersion in water and saline solution, while the flexural modulus was less affected. At $60^{\circ} \mathrm{C}$, the laminate A presented flexural strength retentions of $68 \%$ and $53 \%$ after immersion in water and saline solution, respectively. For laminate $\mathrm{B}$, the flexural strength retention was $68 \%$ and $69 \%$ for immersion in water and saline solution, respectively. The flexural strength of laminate $\mathrm{C}$ was less affected by those types of immersions, with retention of $89 \%$ (in water) and $99 \%$ (in saline solution), at $60^{\circ} \mathrm{C}$.

The large flexural strength reductions observed in laminate A after immersion in alkaline solution at $23^{\circ} \mathrm{C}$ and $40^{\circ} \mathrm{C}$ is a clear indicator of its degradation. The same type of behaviour was observed for laminate B at the three testing temperatures. In fact, as can be seen in Figure 3, test specimens of laminates $\mathrm{A}$ and $\mathrm{B}$ after the immersion in alkaline solutions at different temperatures have shown separation of carbon fibres accompanied by the polymeric matrix release.

The hygrothermal ageing of laminates by continuous condensation at $40^{\circ} \mathrm{C}$ promotes an increase in flexural strength, besides the little decrease observed on modulus. All types of laminates aged in QUV and xenon chambers increased the flexural strength and decreased the modulus. This behaviour seems to be a direct result of postcuring of the epoxy matrix due to exposure to temperature and ultraviolet radiation (UV) radiation.

\subsection{Dynamic mechanical analysis}

Figures 4-6, show experimental dynamic mechanical curves for laminates A, B and C, respectively, after submission to the different ageing conditions (for each condition, only one curve corresponding to a typical tested specimens is shown). At the left, plots show changes in dynamic storage modulus $\left(E^{\prime}\right)$ with temperature, for the different exposure conditions; the corresponding tan $\delta$ curves are shown at the right.

Changes in the storage modulus behaviour reflect changes in the polymer matrix (and/or fiber-matrix interface) because the carbon fibre modulus does not change in the temperature region studied. In measuring storage modulus by DMA, using cantilever geometry the measured properties are sensitive to changes in the matrix.

In general, the immersion in water and saline solution generated a slight reduction in the storage modulus, as well as in the $T_{\mathrm{g}}$ value. For laminates $\mathrm{A}$ and $\mathrm{C}$, the maximum $T_{\mathrm{g}}$ decreasing was observed at the higher immersion temperatures (up to $8 \%$ for laminate A and $10 \%$ for laminate $\mathrm{C}$ ). These results show substantial evidence of plasticisation.
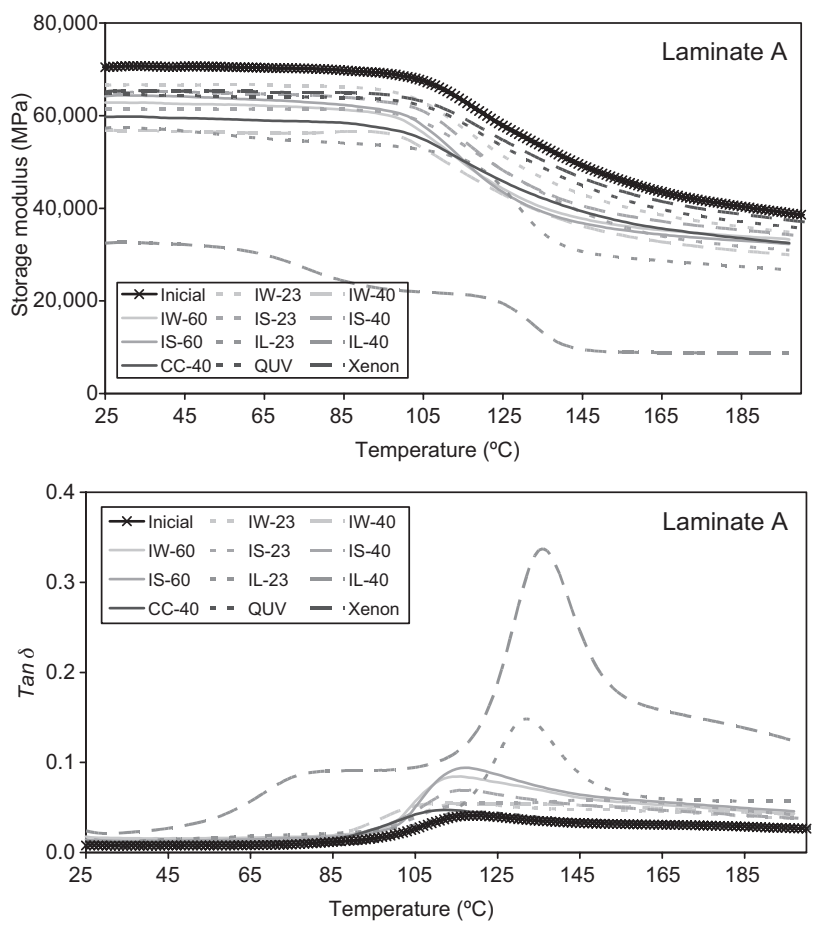

Figure 4 DMA experimental curves for laminate A after different ageing conditions.

Laminate B presented the same trend, with different $\tan \delta$ peak sharp. In this case, it is interesting to note that an additional peak was exhibited at higher temperatures in all experimental curves. The occurrence of two $\tan \delta$ peaks may be attributed to the different mobility of two kinds of segments in the polymeric matrix, due to their different extension of plasticisation. A similar behaviour was found in the hygrothermal ageing of epoxy resins $[15,16]$.

For all laminates, the samples exposed to UV radiation ageing have shown stiffness and $T_{\mathrm{g}}$, increases, probably due to a polymeric matrix post-cure, as it was already mentioned in the flexural testing discussion.

\subsection{FTIR analysis}

Figures 7-9 show infrared spectra determined on the laminates ( $\mathrm{A}, \mathrm{B}$ and $\mathrm{C}$, respectively) after submission to the different ageing conditions.
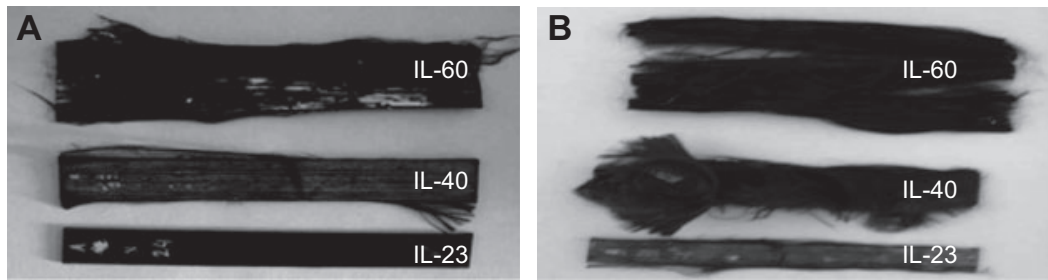

Figure 3 Test specimens of laminates A and B after immersion in alkaline solution at different temperatures. 

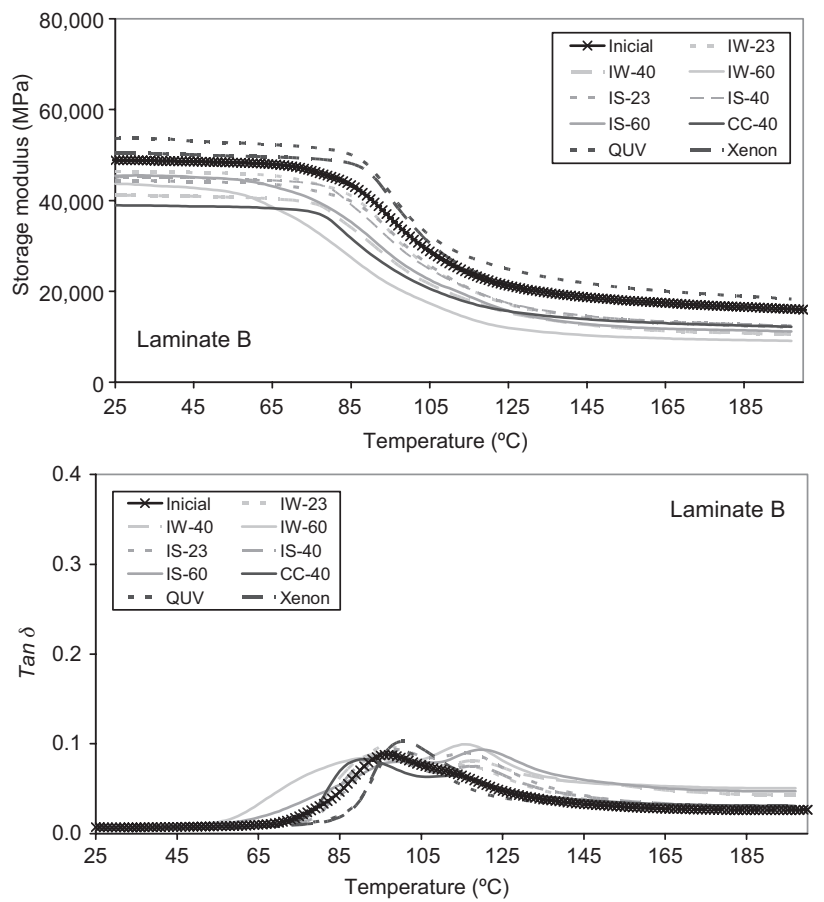

Figure 5 DMA experimental curves for laminate B after different ageing conditions.

Relative to the unaged spectrum, very few changes were observed in the infrared spectra of laminates after immersion in water and saline solution. This fact gives important evidences that the degradation mechanisms are physical, but not chemical, in nature. After immersion in alkaline solutions,
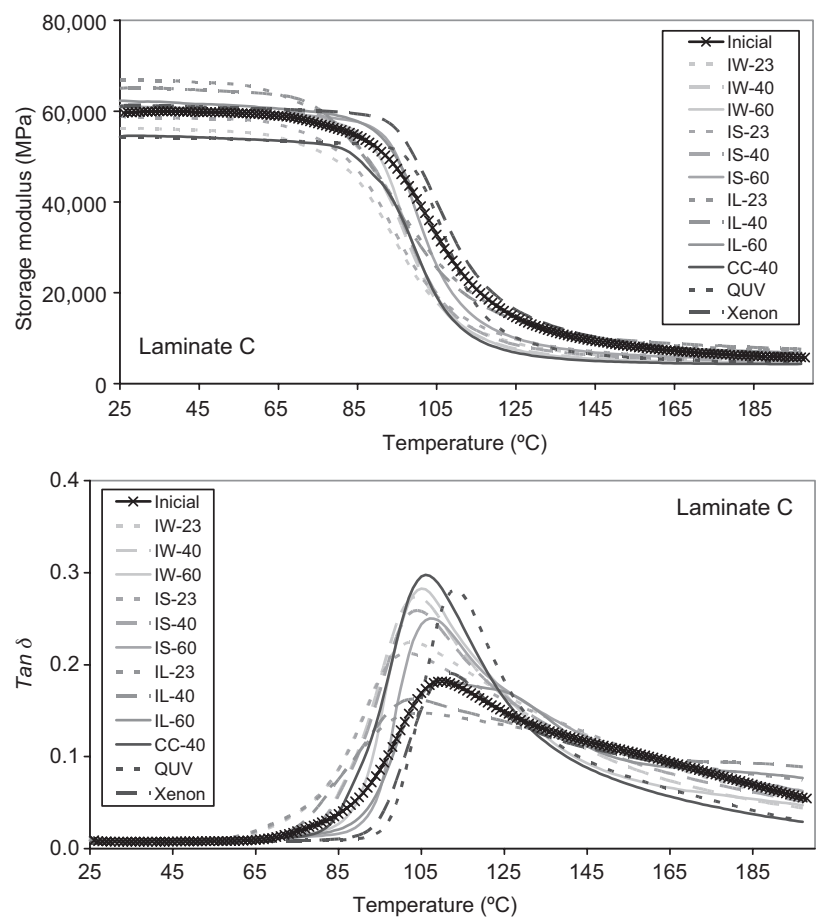

Figure 6 DMA experimental curves for laminate $\mathrm{C}$ after different ageing conditions. spectra show little changes for laminate A and C, but clear evidences signs of chemical degradation in the case of laminate $\mathrm{B}$, where important infrared absorption peaks presented different position and intensity.

Exposition to UV radiation in the xenon chambers exhibited the greatest change in band position and intensity. These spectral changes are consistent with chemical degradation observed in the surface layer of composites. Previous studies on the UV degradation of epoxies have showed that both crosslinking and chain scission mechanisms operate in a competing manner during the degradation process [17].

\section{Conclusions}

Based on the results of the present work, the following conclusions may be taken:

1. Immersion in water and saline solution may had a noticeable effect on the flexural strength of CFRP, but the degree of the retention after ageing depends on the type of laminate. Nevertheless, the degradation is mainly due to physical phenomena, such as plasticisation of the polymeric matrix, since no appreciable chemical degradation was revealed by FTIR.

2. Alkaline solution caused the most severe degradation in all laminates, but was particularly harsh for laminate B which undergoes degradation even at room temperature.

3. The hygrothermal ageing during continuous condensation caused the same effects of water immersion at the same temperature, for all laminates.

4. Besides the chemical degradation that was detected in the FTIR experiments, the ageing conditions which involved UV radiation (QUV and xenon) have been shown to not affect the flexural properties. These results confirm that the degradation is confined to the top of the surface of laminates, having limited influence on their mechanical behaviour.

The presence of alkaline salts in aqueous solution has shown to cause higher levels of deterioration (in the case of laminate C) and/or total deterioration (for the other types of laminates) than the other two immersion solutions. The higher level of degradation of laminates caused by the alkaline ambient is one of the most important conclusions of this work. In fact, similar commercial CFRP laminates could have very different environmental resistance, particularly, in alkaline aqueous ambient.

For each type of immersion, the temperature increase always has caused the intensification of the degree of degradation, because it increases the rate of diffusion. It can be concluded that temperature may be used as a good accelerator factor in order to predict long-term performance in durability studies.

Clearly, the influence of different conditions in the neighbourhood of the materials could result in distinct consequences on the performance of each type of laminate, as 

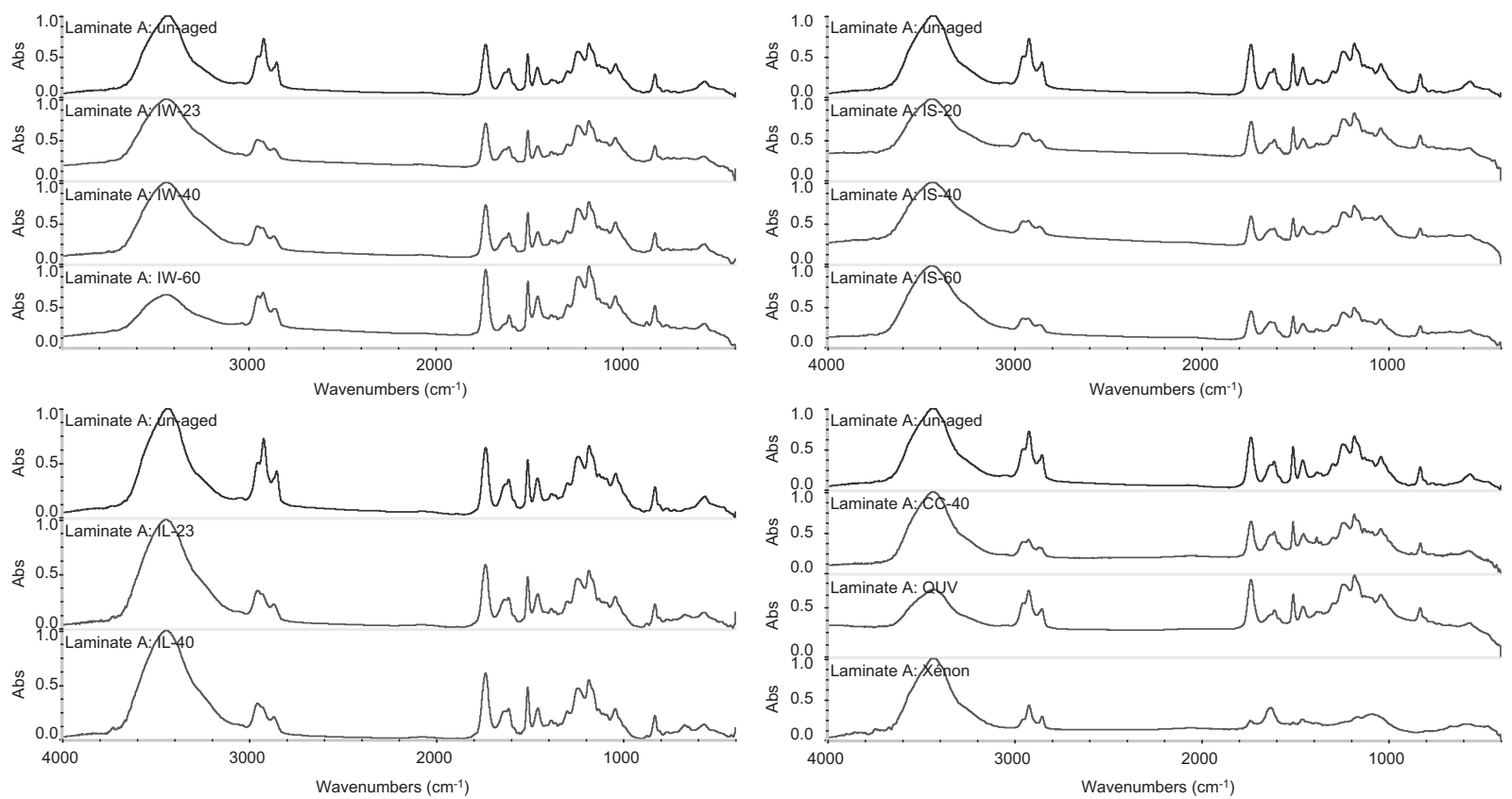

Figure 7 Infrared spectra for laminate A after different ageing conditions.

demonstrated in the present work. Generalisation of these results for other materials and environmental conditions is not straightforward without a complete understanding of the degradation mechanisms involved.

In fact, the durability and long-term performance of CFRP materials have been subjected to much research; however this investigation remains in progress. Furthermore, long-field data are not yet available, and is still difficult to predict accurately the performance of laminates and strengthening systems used in civil engineering. Many issues regarding bonding of the CFRP system to the substrate also remain the focus of a great deal of research.
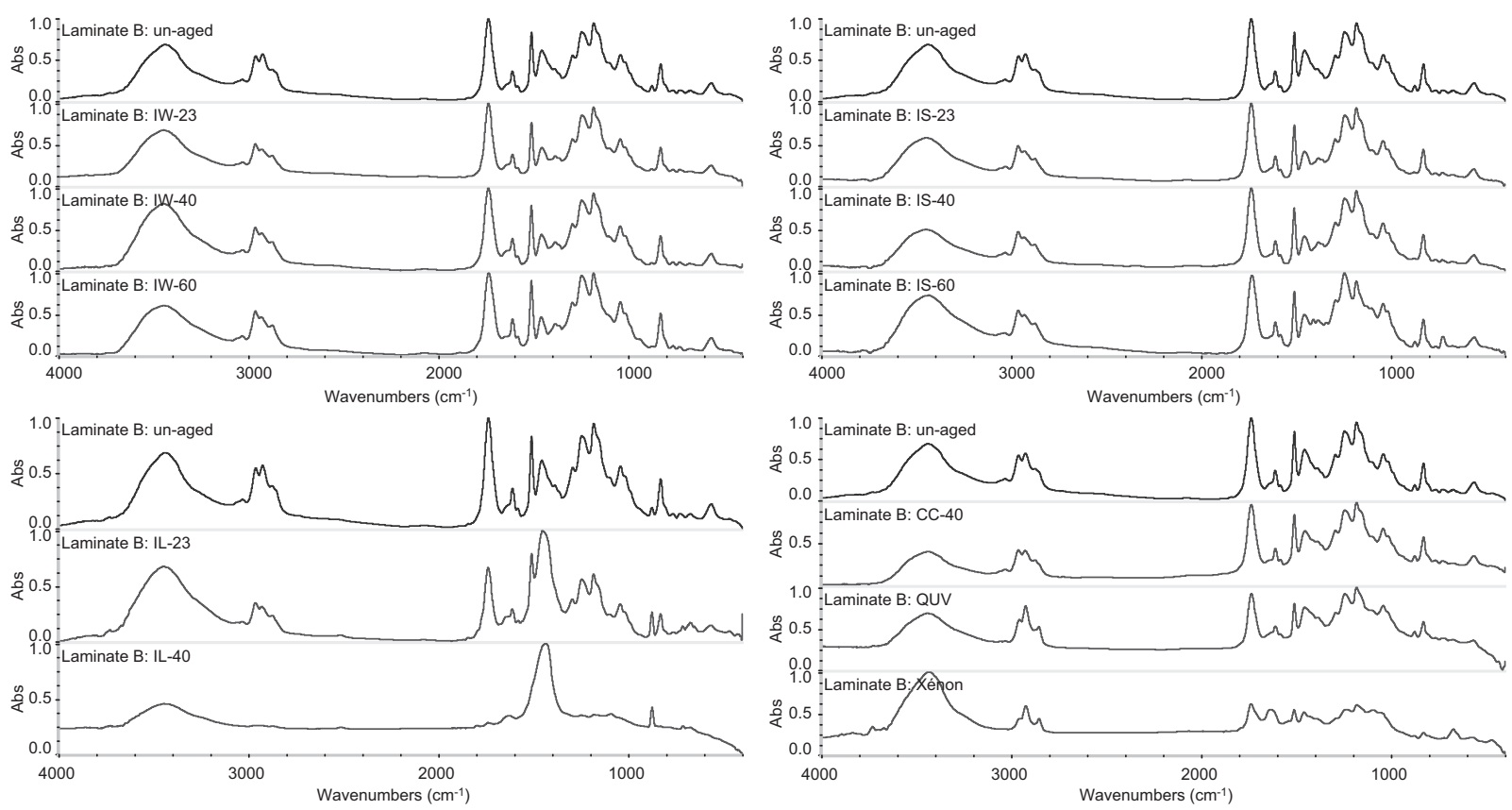

Figure 8 Infrared spectra for laminate B after different ageing conditions. 

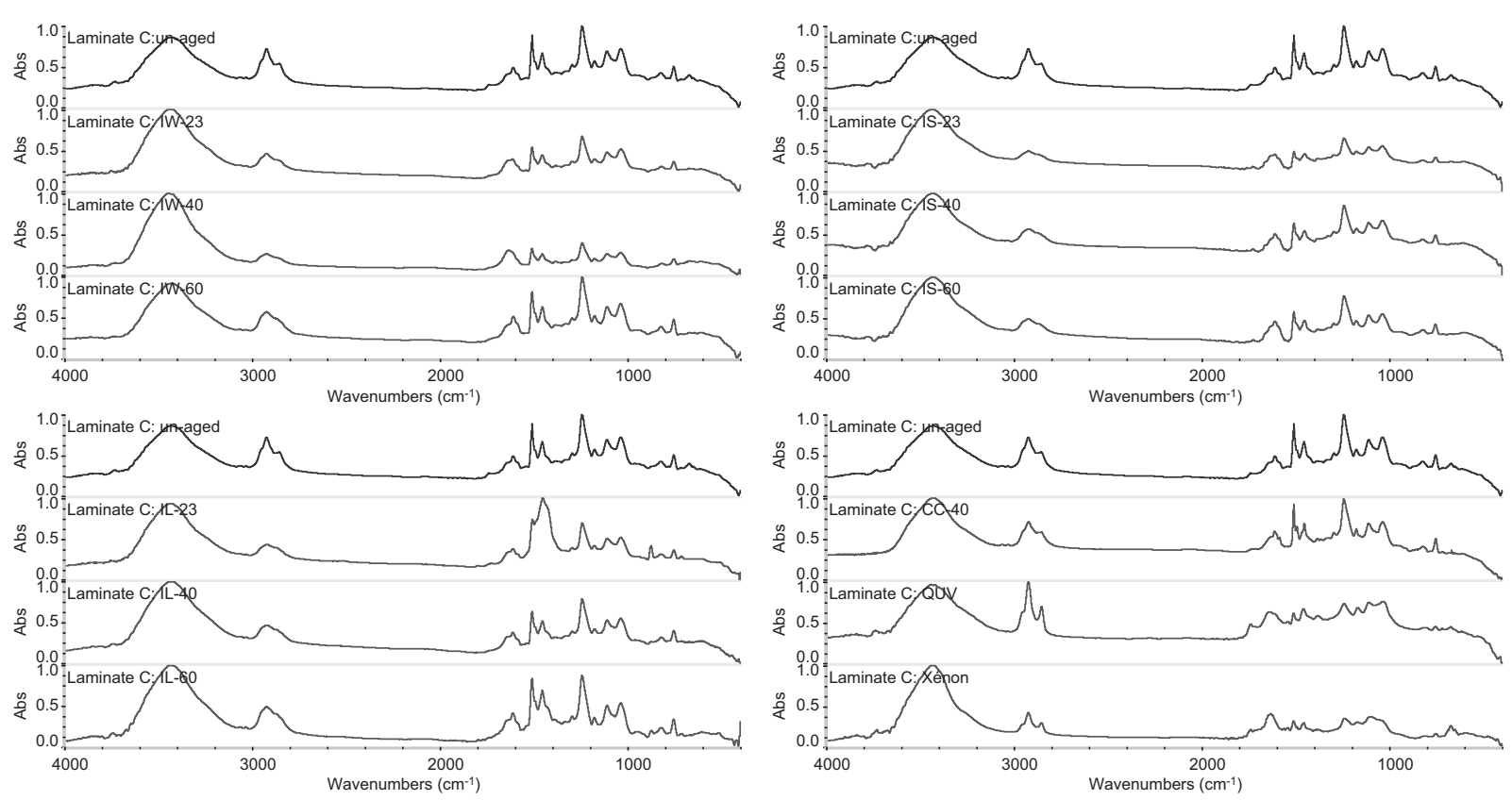

Figure 9 Infrared spectra for laminate $\mathrm{C}$ after different ageing conditions.

\section{References}

[1] Hollaway LC. Constr. Build. Mater. 2003, 17, 365-378.

[2] American Concrete Institute - Committee 440. State-of-the-Art Report on Fiber Reinforced Plastic Reinforcement for Concrete structures, ACI 440R-96. ACI: Farmington Hills, MI, 1996.

[3] Fédération Internacionale du Béton. Externally Bonded FRP Reinforcement for RC Structures, FIB - Technical Report in the Design and Use of Externally Bonded Fibre Reinforced Polymer Reinforcement (FRP EBR) for Reinforced Concrete Structures. FIB: Lausanne, 2001.

[4] American Concrete Institute. ACI Manual of Concrete PracticePart 5 - Guide for the Design and Construction of Externally Bonded FRP systems for Strengthening Concrete Structures, ACI 440.2R-96. ACI: Farmington Hills, MI, 2002.

[5] EN 1504-4. Products and Systems for the Protection and Repair of Concrete Structures - Definitions, Requirements, Quality Control and Evaluation of Conformity. Part 4: Structural Bonding. 2004.

[6] Bank LC, Gentry TR, Thompson BP, Russell JS. Constr. Build. Mater. 2003, 17, 405-437.

[7] Kharbari VM, Chin JW, Hunston D, Benmokrane B, Juska T, Morgan R, Lesko JJ, Sorathia U, Reynaud D. J. Compos. Constr. 2003, 7, 238-247.
[8] Liao K, Schultheisz CR, Hunston DL, Brinson LC. J. Adv. Mater. 1998, 30, 3-40.

[9] Karbhari VM. Seible F. Appl. Compos. Mater. 2000, 7, 95-124.

[10] ISO 4892-1/3. Plastics - Methods of Exposure to laboratory Light Sources. Part 1: General Guidance; Part 3: Fluorescent UV Lamps. 1994.

[11] ISO 4892-1/2. Plastics: Methods of Exposure to Laboratory Light Sources. Part 1: General Guidance; Part 2: Xenon-arc Sources. 1994.

[12] ISO 14125.Fibre-reinforcedPlastic Composites-Determination of Flexural Properties. 1998.

[13] ISO 6721. Plastics - Determination of dynamic Mechanical Properties. Part 1: General Principles. 2001; Part 5: Flexural Vibration - Non-resonance Method. 1996.

[14] Earl JS, Shenoi RA. Composites: Part A 2004, 35, 12371247.

[15] Papanicolau GC, Kosmidou TV, Vatalis AS, Delides CG. J. Appl. Polym. Sci. 2006, 99, 1328-1339.

[16] Nogueira P, Ramírez C, Torres A, Abad MJ, Cano J, López J, López-Bueno I, Barral L. J. Appl. Polym. Sci. 2001, 80, 71-80.

[17] Kumar BG, Singh RP, Nakamura T. J. Compos. Mater. 2002, 36, 2713-2733. 